\title{
Maximizing Blad-containing oligomerfungicidal activity in sweet cultivars of Lupinus albus seeds
}

\section{Filipe Cruz, Paula Batista-Santos*, Sara Monteiro, João Neves-Martins, Ricardo Boavida Ferreira}

Plants for Health and Nutrition, LEAF (Linking Landscape, Environment, Agriculture and Food), Instituto Superior de Agronomia, Universidade de Lisboa, Tapada da Ajuda, 1349-017 Lisbon, Portugal;

* Corresponding author: pbbsantos@isa.ulisboa.pt; pbbsantos@ hotmail.com

\section{ABSTRACT}

During seed germination and plantlet growth, an important aspect of Lupinus $\beta$-conglutin proteolysis is the accumulation of blad in the cotyledons. Blad, a $20.4 \mathrm{kDa}, 173$ residue polypeptide which inhibits fungal growth, is the main subunit of BCO (Blad-containing oligomer), a Lupinus bioactive polypeptide oligomer, which underwent a successful translational research during the last thirty years. The development of this recent broad-spectrum biological fungicide for plant disease control made evident the advantage of being non-toxic to the environment, plants, humans and other animals, an interesting characteristic given the increasing consumer's concern about food safety. The industrial-scale production of the edible fungicide BCO for agricultural purposes involves germinating and growing for ca. 8 days massive amounts of Lupinus plantlets. Therefore, it becomes economically relevant to maximize/increment the amount of extractable BCO. Although BCO represents an alternative pathway for lupin production in Europe, there is no previous evidence on lupin cultivars concerning BCO activity or its cotyledonary concentration, and therefore on the most promising cultivars for BCO extraction and fungicide production. In this work, the amount of BCO and its level of fungicide activity was evaluated in seven sweet cultivars of $L$. albus (cvs. Amiga, Energy, Estoril, Ludic, Misak, Multitalia and Rumbo), along 20 days after the onset of germination. In addition, four distinct lots of cv. Energy and six lots of cv Misak, with different harvest years (1997, 2010, 2013 and 2014) and/or different sites of production in Portugal (Alto Alentejo, Baixo Alentejo and Beira Litoral) were also analysed. Quantitative assays demonstrated maximal accumulation of BCO in the cotyledons of 4-days-old L. albus plantlets, apart from significant differences between seeds' harvest year or production site. The assays also showed that cv. Energy had significant higher accumulation of BCO (31.67 $\mu \mathrm{g} \mathrm{mg}^{-1}$ wet weight) than Rumbo $\left(25.67 \mu \mathrm{g} \mathrm{mg}^{-1}\right)$ and Misak $\left(22.12 \mu \mathrm{g} \mathrm{mg}^{-1}\right)$, respectively second and third cultivars with highest accumulation of the oligomer. Additionally, very significant differences were also observed among seeds' harvest year or production site. These observations reduced 
dramatically the original purpose of this work on the study of BCO variations at the level of sweet L. albus cultivars, since the 'noise' detected in BCO levels caused by the year and location of their production was far greater than its variation among cultivars. The observation that storing for several years the seeds at $-20^{\circ} \mathrm{C}$ did not seem to decrease $\mathrm{BCO}$ activity and suggests that the variation in cotyledonary BCO accumulation is essentially controlled by the prevailing edaphoclimatic conditions during seed formation.

Furthermore, the activity tests exhibited significant antifungal activity between 3 and 5 days-old plantlets, with absence of antifungal activity on 8 days-old plantlets or older. Overall this study is of considerable importance to maximize BCO extraction from the cotyledons of sweet L. albus cultivars.

Keywords: Blad, BCO, Lupinus albus, antifungal activity, fungicide production, seed germination

\section{Introduction}

Climate change may severely influence the effects of plant diseases and pests on crop production, through altered spread of some species and introduction of new pathogens and vectors, leading to uncertain dynamics of plant epidemics (Garrett et al., 2006). $\mathrm{CO}_{2}$ enrichment, $\mathrm{N}$ deposition, and changes in temperature and rainfall regimes increase the infection patterns of fungal plant pathogens (Tylianakis et al., 2008). This could potentially lead to an increase in the number of infection events that in turn could determine an increment in the application of agrochemicals (Hannukkala et al., 2007). Additionally, to feed the over 7 billion people that currently inhabit the planet it does not seem to have any practical option but to use massive applications of chemical, toxic fungicides. Such applications result in several negative effects, including development of resistance among the target microorganisms, toxicity to humans, animals and other nontarget organisms, and long environmental retention periods leading to residual toxicities and environmental pollution (Paster and Barkai-Golan, 2008; Raja, 2014; Gakuubi et al., 2017). In an attempt to reduce the toxicity of synthetic fungicides, increased research was dedicated to the search for alternatives to the toxic fungicides for management of pathogenic fungi. The search for compounds of biological origin was at the forefront. Phytochemicals have been recognized as some of the most promising compounds for the development of novel and ecofriendly phytofungicides (Reddy et al., 2007; Anjorin et al., 2013). The primary advantages of using plant-derived antimicrobials in comparison to synthetic chemicals are their lower mammalian toxicity, higher degradability, multiple mechanisms of action, and fewer incidences of the numerous side effects often associated with synthetic chemicals (Raja, 2014). On the other hand, biological fungicides, such as the bacterium Bacillus subtilis or the fungus Trichoderma spp, may imbalance the microbiota 
equilibrium typical of many natural environments and frequently need to be re-applied more often than conventional fungicides. Ideally the discovery and development of nontoxic fungicides could provide a valid alternative.

BCO (for Blad-Containing Oligomer), an example of translational research undertaken since its discovery in 1991, is an edible $210 \mathrm{kDa}$ polypeptide oligomer composed of a mixture of $\beta$-conglutin fragments, with blad $(20.4 \mathrm{kDa})$ as its major subunit. $\beta$-Conglutin is a globulin and the major storage protein from Lupinus seeds (Melo et al., 1994; Ferreira et al., 1999), whereas blad, BCO bioactive subunit, is a 173 amino acid residue polypeptide which comprises residues 109 to 281 of the precursor of $\beta$-conglutin (i.e. pro- $\beta$ conglutin) (Monteiro et al., 2010). Under natural conditions, BCO accumulates in the cotyledons of Lupinus seedlings between the $4^{\text {th }}$ and $14^{\text {th }}$ day after the onset of germination, as a stable breakdown product of $\beta$-conglutin catabolism (Ramos et al., 1997).

Blad exhibits lectin activity (Ramos et al., 1997; Ferreira et al., 2003) and also the catalytic activities of $\beta$ - $N$-acetyl-Dglucosaminidase and of chitosanase (Monteiro et al., 2015). BCO is non-toxic to plants and animals, humans included, an interesting feature given the consumer's concern about food safety. It exhibits a potent, broad spectrum fungicide activity against all fungal species tested, including human, animal and plant pathogens, food spoiling and food poisoning fungi. BCO also shows a strong plant growth biostimulant activity and a weak bactericide activity towards Gram- bacteria.

Blad bioactivity survives very high temperatures and extreme $\mathrm{pH}$ values, exposure to organic solvents and detergents. It is particularly sensitive to proteolytic attack and to any other condition that leads to peptide bond cleavage (Monteiro et al., 2010). BCO finds application under real, open air agriculture, withstanding the effect of UV sunlight and producing results which equal or exceed those of the commercially available chemical pesticides. Its mechanism of action is multitarget (Pinheiro et al., 2017), suggesting a low probability for the development of resistance mechanisms by the target pathogens. It is included in the FRAC (Fungicide Resistance Action Committee) Code List@2020_Fungicides sorted by mode of action as a Biological with multiple modes of action, with the BM01 FRAC code, and has been certified in the US by OMRI (Organic Materials Review Institute; product number cev-10083) for use in organic farming. Several blad applications are protect by four patent families, PCT International Patent Application nos.

PCT/IB2006/052403, PCT/EP2011/067824, PCT/EP2011/067821 and PCT/EP2011/067828 (Ferreira et al., 2006; Carreira et al., 2011a, 2011b, 2011c).

BCO for agricultural application is currently produced at an industrial plant in Cantanhede, Portugal, from Lupinus albus sweet cultivars, to eliminate the presence of toxic levels of alkaloids in the final fungicidal formulation. It is now being sold for agricultural 
purposes in a number of countries and is expected to hit the European market by late 2021. Countries in which BCO is currently on sale and those which are soon expected to commercialize $\mathrm{BCO}$ are given at http://www.cev.com.pt/en/markets/. The development of BCO to treat human fungal infections has certainly a huge potential (e.g. Malassezia spp.) (Pinheiro et al., 2016; Carreira et al., 2018).

Detailed structural studies performed over the last years on both BCO and blad, as well as attempts to produce recombinant blad and a number carefully selected blad variants led to the conclusion that it will be extremely difficult if not impossible, to produce recombinant $\mathrm{BCO}$ and/or blad in sufficient amount at a feasible price. Its production will therefore rely on the massive germination and plantlet growth for ca. 8 days of sweet Lupinus cultivar seeds, followed by an appropriate extraction methodology.

Incrementing/maximising the amount of extractable $\mathrm{BCO}$ would therefore be highly relevant and come as a first priority for the $\mathrm{BCO}$ industry.

Although BCO represents an alternative way for fungal control in agricultural crops, and in particular in those climates and environments (e.g. rich, intensive crops cultivated under greenhouse conditions) which are highly favourable for fungal growth, and may increase industrial interest on lupin production, up to now there is no evidence about the most promising sweet cultivars of $L$. albus for $\mathrm{BCO}$ extraction and fungicide production. Also the edaphoclimatic conditions that prevail in the life cycle of seed prodution and the variation in BCO fungicide activity during the period in wich it accumulates in the cotyledons are not yet studied. To obtain this information, quantitative and activity assays were implemented in this study.

\section{Materials and methods}

\subsection{Biological material and growth conditions}

Dry seeds of white lupin (Lupinus albus L.) cvs. Amiga, Energy, Estoril, Ludic, Misak, Multitalia and Rumbo were kindly supplied by CEV/CONVERDE (Cantanhede, Portugal; the commercial manufacturer of BCO for agricultural purposes) and LusoSem (Oeiras, Portugal; a company which commercializes lupin seeds). In addition, four lots of cv. Energy and six different lots of cv. Misak, with different harvest years (1997, 2010, 2013 and 2014) and/or origin sites in Portugal (Alto Alentejo, Baixo Alentejo and Beira Litoral), were kindly supplied by Prof. J. Neves-Martins, responsible for the Lupinus germoplasm bank at Instituto Superior de Agronomia, University of Lisbon (ISA). L. albus seeds were harvested and stored permanently at $-20^{\circ} \mathrm{C}$ until used in the assays. 

and incubated at $25^{\circ} \mathrm{C}$ for periods up to 20 days in a $16 / 8 \mathrm{~h}$ light/dark cycle under fluorescent lamps. The plantlets were watered as required with water. In the present study, the seed coats were removed by hand from plantlets aged between 4 and 12 -days-old, with intact cotyledons from each cultivar dissected from the axes, weighed, frozen in liquid nitrogen and stored at $-80^{\circ} \mathrm{C}$ until needed. All samples were analysed in triplicate. Under industrial conditions, these procedures have been automatized.

Fungal strains tested for Minimum Inhibitory Concentration (MIC) values were obtained from Instituto Superior de Agronomia's culture collection (Candida glabrata, ISA 2163) or isolated by CEV/CONVERDE's lab (Botrytis cinerea, CEV 6, isolated from tomato). B. cinerea strain was previously identified by sequence analysis of the internal transcribed spacer (ITS) region of the ribosomal DNA (PCR amplification with ITS1 and ITS4 primers).

For preparing the inocula, B. cinerea was grown on Potato Dextrose Agar (PDA) for 7 days at $25^{\circ} \mathrm{C}$ and $C$. glabrata was grown on Glucose Yeast Peptone (GYP) agar for 24 hours at $37^{\circ} \mathrm{C}$.

\subsection{Purification of total soluble proteins}

Total soluble proteins were extracted and purified by a modification of the Blagrove and Gillespie method (1978), as described by Santos et al. (1997). The cotyledons from L. albus plantlets were ground and homogenized with a mortar and pestle, with total cotyledonary protein extracted in globulin solubilizing buffer: $2.5 \mathrm{~mL} \mathrm{~g}^{-1}$ fresh weight, $100 \mathrm{mM}$ Tris-HCl buffer, $\mathrm{pH} 7.5$, containing $10 \%$ (w/v) $\mathrm{NaCl}, 10 \mathrm{mM}$ EDTA and $10 \mathrm{mM}$ EGTA. The homogenized solution was agitated during $30 \mathrm{~min}$ at $4^{\circ} \mathrm{C}$, squeezed through two layers of cheesecloth and centrifuged at $15.000 \mathrm{~g}$ for $1 \mathrm{~h}$ at $4^{\circ} \mathrm{C}$. The resulting supernatant was desalted on PD-10 columns (GE HealthCare Life Sciences; disposable desalting Sephadex G-25 Medium columns, $9.1 \mathrm{~mL}$ bed volume) previously equilibrated in $50 \mathrm{mM}$ Tris-HCl buffer, $\mathrm{pH} 7.5$.

\subsection{Purification of the glyco-oligomer containing blad}

The total soluble protein fraction was fractionated and subsequently purified by anion-exchange fast protein liquid chromatography (苂TAFPLC) on a Resource ${ }^{\mathrm{TM}} \mathrm{Q}$ column equilibrated with $50 \mathrm{mM}$ Tris-HCl buffer (pH 7.5; GE HealthCare Life Sciences, Uppsala, Sweden; Monteiro et al., 2010). Blad (main breakdown product of $\beta$-conglutin catabolism) and the other polypeptides 
which comprise $\mathrm{BCO}$ were eluted with a gradient of $\mathrm{NaCl}(0$ to $1 \mathrm{M})$. For antifungal activity tests, desalting was achieved by dialysis. The presence of blad (20.4 kDa) was detected by SDS-PAGE.

\subsection{Electrophoresis}

All blad-containing samples were boiled for $3 \mathrm{~min}$ in the presence of SDS (2\%, w/v) and 2-mercaptoethanol $(0.1 \mathrm{M})$ and subjected to SDS-PAGE in 10\% (w/v) acrylamide slab gels as described before (Ferreira et al., 1995b). Total polypeptides in gels were stained with

Coomassie Brilliant Blue R.

\subsection{Quantification of the glyco-oligomer containing blad}

The BCO content of the Lupinus extracts was quantified by a spectrophotometrical method, based on BCO molar attenuation coefficient. This value was previously calculated with pure BCO using a modification of the Lowry method (Bensadoun and Weinstein, 1976).

\subsection{Antifungal activity tests - MIC values}

Susceptibility tests of the selected fungal species to BCO were made according to the Reference Methods for Broth Dilution Antifungal Susceptibility Testing guidelines M27-A2 (NCCLS, 2002) and M38-A2 (CLSI, 2008), using the broth microdilution method, with small modifications. As negative controls, experiments were performed in the absence of BCO.

C. glabrata: C. glabrata was grown as described in Pinheiro et al. $(2016,2018)$. The suspension was prepared by covering the colonies with $5 \mathrm{~mL}$ of sterile $0.9 \%(\mathrm{w} / \mathrm{v})$ saline $(\mathrm{NaCl})$ solution and diluted to a turbidity equivalent to that of a $0.5 \mathrm{McFarland}$ standard with a spectrophotometer at $640 \mathrm{~nm}$. The suspension was further diluted (1:50) with Potato Dextrose Broth (PDB) medium (pH 7.5), prepared with a double concentration, to yield an inoculum concentration of approximately $1 \times 10^{3}$ cells $/ \mathrm{mL}$. One hundred $\mu \mathrm{L}$ was added into the wells of each row containing $100 \mu \mathrm{L}$ diluted BCO $\left(0.5 \mathrm{mg} \mathrm{mL}^{-1}\right)$. The final volume in each microplate well was therefore $200 \mu \mathrm{L}$. Microplates were then incubated at $34^{\circ} \mathrm{C}$ without agitation and results were determined after $72 \mathrm{~h}$ by visual inspection.

B. cinerea: B. cinerea was grown as described in Monteiro et al. (2015). The suspension was prepared by covering the fungal colonies with $5 \mathrm{~mL}$ of sterile $0.9 \%(\mathrm{w} / \mathrm{v})$ saline $(\mathrm{NaCl})$ solution containing $0.01 \%(\mathrm{v} / \mathrm{v})$ polysorbate 20 . The suspension was transferred to a sterile tube, mixed in a vortex for $15 \mathrm{~s}$, and the cell density adjusted to $0.4-5.0 \times 10^{6} \mathrm{CFU} / \mathrm{mL}$ by direct counting of spores using a 
Neubauer chamber. The final inoculum suspension was made by a 1:50 dilution with PDB medium (pH 7.5), prepared with a double concentration, which resulted in a final concentration between $0.4 \times 10^{4}$ to $5.0 \times 10^{4}$ cells $/ \mathrm{mL}$. The inoculum size was confirmed by enumeration of CFUs obtained by subculturing on PDA plates. One hundred $\mu \mathrm{L}$ was added into the wells of each row containing $100 \mu \mathrm{L}$ diluted BCO $\left(0.5 \mathrm{mg} \mathrm{mL}^{-1}\right)$. The final volume in each well was therefore $200 \mu \mathrm{L}$. Microplates were then incubated at $25^{\circ} \mathrm{C}$ without agitation and results were determined after $72 \mathrm{~h}$ by visual inspection.

The MIC endpoints were the lowest BCO dilution with no visible growth, as recommended by NCCLS (2002) and CLSI (2008).

\subsection{Statistical analysis}

A statistical computing tool, R 3.2.0, was used to perform a two-way analysis of variance (ANOVA) on each dataset, with mean separation done by Tukey's range test $(P<0.05)$. When any one of the ANOVA assumptions was not observed, ANOVA results were maintained, but confirmed through non-parametric methods: Kruskal-Wallis test and/or Friedman test.

\section{Results and discussion}

\subsection{Quantification of BCO - The effect of cultivar}

The cultivars studied (Amiga, Energy, Estoril, Ludic, Misak, Multitalia and Rumbo) were selected because of their recognized agronomical value and/or high cotyledonary concentration of BCO, as determined by CEV/CONVERDE. The growth and development of lupins during the initial stages of their growing cycle is illustrated in Fig. 1.

Quantification of BCO content in L. albus plantlets was carried out between days 4 and 12 after the onset of germination. This period is justified by the previously determined abrupt accumulation of this oligomer in the cotyledons of Lupinus species during the $4^{\text {th }}$ day after imbibition, maintenance at high levels in these organs during several days, and rapid decline after $12^{\text {th }}$ to $14^{\text {th }}$ days (Ferreira $e t$ al., 1995a; Freitas et al., 2007; Monteiro et al., 2010, 2015). 
It remains to be established the molecular mechanism behind this abrupt accumulation of BCO during the fourth day after the onset of germination, although this may be due to structural changes related to proteolysis of $\beta$-conglutin, the pre-existing seed storage protein (Ferreira et al., 1995b).

The results presented in Table 1 show that the selected cultivars exhibit a maximum accumulation of BCO at the $4^{\text {th }}$ day, followed by a progressive and continuous decrease of this oligomer up to the $12^{\text {th }}$ day, where very low BCO values are present $\left(<5 \mu \mathrm{g} g^{-1}\right.$ fresh weight). As a result of this decrease, it was observed that the quantitative differences in BCO detected among the different cultivars at day 4 vanished along seedling growth due to the proteolytic process.

The statistical analysis revealed significant differences between days 4 and 12 after the onset of germination and also among cultivars, as well as the existence of interactions between these two effects as shown by the differential reduction in BCO along time in the different cultivars.

The cv. Energy presented the highest BCO accumulation, although cvs. Amiga, Misak and Rumbo were also promising cultivars, for its similar agronomic fitness (verified in field trials - data not shown) and high accumulation of the oligomer $\left(>17 \mu \mathrm{g} \mathrm{g}^{-1}\right.$ fresh weight).

Purified BCO was subjected to gel filtration and SDS-PAGE to confirm its native molecular mass of $210 \mathrm{kDa}$, as well as its subunit composition and size. The extracts prepared from different varieties contain variable amounts of BCO. To normalize the results and allow for a quantitative comparison of $\mathrm{BCO}$ among varieties, the volume of 4-days-old, cv. Energy cotyledon BCO-purified extract containing $20 \mu \mathrm{g} \mathrm{BCO}$ was experimentally calculated to correspond to $22.78 \mu \mathrm{L}$. Therefore, $22.78 \mu \mathrm{L}$ of BCO-purified extract from all cultivars were loaded in the gel, which corresponds to the same mass of 4-days-old cotyledonary fresh weight. As reported earlier (Ramos et al., 1997; Monteiro et al., 2010), a simple SDS-PAGE analysis (Fig 2) revealed this oligomer to be composed of several polypeptides, the major ones exhibiting molecular masses of 14, 17, 20 (blad), 32, 36, 48 and $50 \mathrm{kDa}$. A comparison among cultivars showed that BCO polypeptide profile is identical for all of them, although the four cultivars previously indicated (Amiga, Energy, Misak and Rumbo) contain a higher amount of BCO than the other cultivars.

As reported before, BCO polypeptide profile suffered changes over time following the $4^{\text {th }}$ day after the onset of germination (Fig 3 - A). However, the degradation rate did not seem to be the same for all cultivars studied, but rather seemed to be in accordance with the 
statistical analysis previously described (Table 1; time:cultivar interaction). This observation was confirmed by SDS-PAGE, where quite different polypeptide profiles were obtained by analysing a fixed quantity of $\mathrm{BCO}$ obtained during different days after the onset of germination (Fig $3-$ B). The results showed that blad is clearly the most abundant polypeptide band resisting to this kind of proteolytic degradation.

\subsection{Quantification of BCO - The effect of edaphoclimatic conditions}

BCO was quantified in L. albus, but this time comparing factors other than the cultivar, i.e. for the same cultivar (Energy or Misak) seeds produced in different years (and therefore subjected to storage at $-20^{\circ} \mathrm{C}$ for different lengths of time) and in different regions were studied. This assay showed a great heterogeneity among and within the seed lots, i.e., heterogeneity among different batches/lots of the same cultivar and heterogeneity among plants belonging to the same batch (origin site and harvest year - Table 2). Although standard error values were always quite high, these results seem quite consistent, given the high significance of seed lot and cultivar factors, as well as the existence of interactions between these factors.

A careful analysis of the data presented in Table 2 suggests that BCO levels in 4-day-old L. albus cotyledons are dependent on the cultivar and on both the year and the region (collectively on the edaphoclimatic conditions) where the seeds were produced, and do not seem to depend on the length of storage time frozen at $-20^{\circ} \mathrm{C}$. Therefore, the results may be due to effects from cultivar, fertilization, site and region of seed production, harvest year, productivity and/or storage conditions, factors that influence in general the composition and quantity of cellular components (Bosworth et al., 2013; Halvorson et al., 2003; Kallio et al., 2002; Sluis et al., 2001), and which certainly conditioned the plants that produced the seeds analysed in the present work. These new and unexpected results greatly influence the level of extractable $\mathrm{BCO}$, being of enormous interest to the $\mathrm{BCO}$ production industry.

\subsection{BCO antifungal activity tests - MIC value determinations}

Besides functioning as a cotyledonary storage globulin in L. albus, BCO fulfils other physiological roles in the plant, based on the highly remarkable number of distinct biochemical properties exhibited by this oligomer, most notably its catalytic activities, lectin activity and resistance to denaturation (Monteiro et al., 2015). 
To determine BCO anti-fungal activity, one experiment was conducted on Botrytis cinerea, a necrotrophic fungus that affects many plant species, and on C. glabrata, an haploid yeast of the genus Candida which is a closely related opportunistic human pathogen and a model organism often used in antifungal activity experiments (NCCLS, 2002; CLSI, 2008). BCO was obtained from the cotyledons of 3-, 4-, 5-, 8-, 12- and 16-days-old L. albus plantlets, from cvs. Energy and Rumbo, respectively first and second cultivars with the highest accumulation of BCO in the previous quantitative assay (Table 1).

The susceptibility of pathogenic fungi to the oligomer was assessed in vitro by the determination of the MIC, i.e., the lowest BCO concentration that inhibits visible growth of a fungal strain. BCO antifungal activity was tested against the oligomer and the results are shown in Table 3.

The MIC value range was relatively large, but essentially this experiment evidenced quite new and practical results, i.e., BCO demonstrated anti-fungal activity between 3-5 days after the onset of germination (no statistically significant differences) and, surprisingly, no antifungal activity in the cotyledons from 8-, 12- and 16-days-old plantlets (Table 3). The range of BCO concentrations tested were specified in the international standards for this test (CLSI, 2008), and MIC values were also within the common values for this type of test (Bueno et al., 2010; Silva Barros et al., 2007). Although the doses (when expressed in units of mass) of BCO required for fungal inhibition in vitro were higher than those usually required for other antifungal drugs, it should be noted that BCO molecular mass was also substantially higher ( $210 \mathrm{kDa}$; typically by almost two orders of magnitude) that that of commercial fungicides, which means that when expressed on a molar basis or on the number of molecules required to exhibit inhibitory effect, BCO antifungal activity was quite similar to that of the available drugs (Monteiro et al., 2015).

\section{Conclusions}

Several parameters were addressed in the present study. The cultivar, and the year and place of seed production (collectively defining the edaphoclimatic conditions) on $\mathrm{BCO}$ amount and the age of the seedling cotyledons on BCO fungicidal activity. The innovative results obtained were both unexpected and surprising, but of great relevance in what concerns BCO industrial production.

Two major conclusions may be drawn from the results presented in this work: 
- The amount of extractable BCO is not directly related to its fungicidal potency, as they both vary widely in cotyledons during seedling growth in an apparently independent way. Thus, for example, BCO is still present in cotyledons between days 8 and 12 after the onset of germination but is seems to be devoid of fungicide activity. Consequently, judging $\mathrm{BCO}$ fungicide potency by calculating $\mathrm{BCO}$ amount is not an appropriate choice.

- The amount of extractable BCO seems to depend to a much greater extent on the edaphoclimatic conditions prevailing during vegetative growth and seed formation than on the Lupinus cultivar.

Specific and detailed physiological and agronomical studies should therefore be conducted to identify the edaphoclimatic conditions during plant growth, as well as the seed storage conditions after harvest and the germinating and plantlet growth duration and conditions, in order to optimize all these variables in a way to maximize extractable BCO fungicidal activity.

As BCO industrial production requires massive germination and plantlet growth of sweet Lupinus plants for ca. 8 days, followed by a suitable extraction methodology, incrementing/maximising the amount of extractable BCO is therefore highly relevant and comes as a priority for the $\mathrm{BCO}$ industry.

\section{Acknowledgements}

This work was supported by national funds through the Project PRODER +Lupinus - PA46196 (including the fellowship to Filipe Cruz) and via Fundação para a Ciência e a Tecnologia through the research unit UID/AGR/04129/2020 (LEAF). The authors wish to thank CEV/CONVERDE (Cantanhede, Portugal) and Lusosem (Oeiras, Portugal) for kindly supplying lupin seeds from different cultivars.

\section{References}

Anjorin, T.S., Salako, E.A., Makun, H. A., 2013. Control of toxigenic fungi and mycotoxins with phytochemicals: potentials and challenges, in: Makun, H.A. (Ed.), Mycotoxin and Food Safety in Developing Countries. InTech, Rijeka, Croatia, pp. 181-202. http://dx.doi.org/10.5772/53477

Bensadoun, A., Weinstein, D., 1976. Assay of proteins in the presence of interfering materials. Anal. Biochem. 70, $241-250$. https://doi.org/10.1016/S0003-2697(76)80064-4

Blagrove, R.J., Gillespie, J.M., 1978. Comparative studies on the proteins from seeds of Lupinus angustifolius L. Aust. J. Plant Physiol. 5, 651-663. https://doi.org/10.1071/PP9780651 
Bosworth, S.; Kelly, T.; Monahan, S., 2013. Nitrogen Fertilization, Time of Harvest and Soil Drainage Effects on Switchgrass Biomass Production and Fuel Quality. Vermont Grass Biomass Energy - Research Report, pp. 1-8.

Bueno et al., 2010. In vitro activity of fluconazole, itraconazole, voriconazole and terbinafine against fungi causing onychomycosis. Clin. Exp. Dermatol. 35 (6), 658-663. DOI: 10.1111/j.1365-2230.2009.03698.x

Carreira et al., 2018. Blad-Containing Oligomer: a novel fungicide used in crop protection as an alternative treatment for tinea pedis and tinea versicolor. J Med Microbiol. 67, 198-207. doi: 10.1099/jmm.0.000675

Carreira, A.M.L., Monteiro, S.A.V.S., Ferreira, R.M.S.B., 2011a. Patent BLAD-A: Lupinus protein for use against human pathogens. PCT International Patent Application no. PCT/EP2011/067824.

Carreira, A.M.L., Monteiro, S.A.V.S., Ferreira, R.M.S.B., 2011b. Patent BLAD-B: Use of a composition comprising an antimicrobial peptide as a food preservative. PCT International Patent Application no. PCT/EP2011/067821.

Carreira, A.M.L., Monteiro, S.A.V.S., Ferreira, R.M.S.B., 2011c. Patent BLAD-C: Metals chelators for use in improving activity of fungicides / bactericides effective against plant pathogens. PCT International Patent Application no. PCT/EP2011/067828.

CLSI, 2008. Reference method for broth dilution antifungal susceptibility testing of filamentous fungi. Approved Standard. Second edition, document M38-A2. Clinical and Laboratory Standards Institute, Wayne, PA. Clinical and Laboratory Standards Institute.

Ferreira, R.B., Franco, E., Teixeira, A.R., 1999. Calcium- and magnesium-dependent aggregation of legume seed storage proteins. $J$. Agric. Food Chem. 47, 3009-3015. https://doi.org/10.1021/jf981151c

Ferreira, R.B., Freitas, R.L., Teixeira, A.R., 2003. Self-aggregation of legume seed storage proteins inside the protein storage vacuoles is electrostatic in nature, rather than lectin mediated. FEBS Letters, 534, 106-110. doi:10.1016/S0014-5793(02)03801-2

Ferreira, R.B., Melo, T.S., Teixeira, A.N., 1995a. Catabolism of seed storage proteins from Lupinus albus - Fate of globulins during germination and seedling growth. Aust. J. Plant Physiol. 22, 373-381.

Ferreira et al., 1995b. Changes in ubiquitin and ubiquitin-protein conjugates during seed formation and germination. J. Exp. Bot. 46, 211219. https://doi.org/10.1093/jxb/46.2.211

Ferreira et al., 2006. Patent BLAD: Protein extracted from plants of the genus Lupinus or produced in recombinant form, nucleotide sequence encoding it and its use in animal nutrition, as a plant growth promoter and in the fight against pathogenic fungi. PCT International Patent Application no. PCT/IB2006/052403.

Freitas, R.L., Teixeira, A.R., Ferreira, R.B., 2007. Vicilin-type globulins follow distinct patterns of degradation in different species of germinating legume seeds. Food Chem. 102, 323-329. https://doi.org/10.1016/j.foodchem.2006.05.023

Gakuubi, M.M., Maina, A.W., Wagacha, J.M., 2017. Antifungal Activity of Essential Oil of Eucalyptus camaldulensis Dehnh against Selected Fusarium spp. Int J Microbiol. 2017:8761610. https://doi.org/10.1155/2017/8761610

Garrett et al., 2006. Climate change effects on plant disease: genomes to ecosystems. Annu. Rev. Phytopathol. 44, 489-509. doi:10.1146/annurev. phyto.44.070505.143420

Halvorson, A., Mosier, A., Reule, C., 2003. Irrigated Crop Management Effects on Productivity, Soil Nitrogen \& Soil Carbon. Proceedings of 2003 Fertilizer Industry Round Table, pp. 1-12.

Hannukkala et al., 2007. Lateblight epidemics on potato in Finland 1933-2002; increased and earlier occurrence of epidemics associated with climate change and lack of rotation. Plant Pathol. 56, 167-176. https://doi.org/10.1111/j.1365-3059.2006.01451.x 
Kallio, H., Yang, B., Peippo, P., 2002. Effects of Different Origins \& Harvesting Time on Vitamin C, Tocopherols and Tocotrienols in Sea Buckthorn (H. rhamnoides) Berries. J. Agric. Food Chem., 50: 6136-6142. https://doi.org/10.1021/jf020421v

Melo, T.S., Ferreira, R.B., Teixeira, A.N., 1994. The seed storage proteins from Lupinus albus seeds. Phytochemistry 37, $641-648$. https://doi.org/10.1016/S0031-9422(00)90331-5

Monteiro et al., 2010. The unique biosynthetic route from Lupinus $\beta$-conglutin gene to blad. PLoS ONE. 5(1), e8542. doi:10.1371/journal.pone.0008542

Monteiro et al., 2015. A nontoxic polypeptide oligomer with a fungicide potency under agricultural conditions which is equal or greater than that of their chemical counterparts. PLoS ONE. 10(4), e0122095. doi:10.1371/journal.pone.0122095

NCCLS, 2002. Reference method for broth dilution antifungal susceptibility testing of yeasts, Approved Standard. Second edition, document M27-A2. National Committee for Clinical Laboratory Standards, Wayne, Pa.

Paster, N., Barkai-Golan, R., 2008. Mouldy fruits and vegetables as a source of mycotoxins: part 2. World Mycotoxin J. 1(4), $385-396$. https://doi.org/10.3920/WMJ2008.x044

Pinheiro et al., 2018. Fusion proteins towards fungi and bacteria in plant protection. Microbiology. 164, 11-19. https://doi.org/10.1099/mic.0.000592

Pinheiro et al., 2017. Bridging the gap to nontoxic fungal control: Lupinus-derived Blad Containing Oligomer as a novel candidate to combat human pathogenic fungi. Front. Microbiol. 8, 1182. doi: 10.3389/fmicb.2017.01182

Pinheiro et al., 2016. Blad-containing oligomer fungicidal activity on human pathogenic yeasts. From the outside to the inside of the target cell. Front. Microbiol. 7, 1803. doi: 10.3389/fmicb.2016.01803

Raja, N., 2014. Botanicals: sources for eco-friendly biopesticides. J Biofertil Biopestici. 5, e122. doi:10.4172/2155-6202.1000e122

Ramos et al., 1997. Accumulation of a lectin-like breakdown product of $\beta$-conglutin catabolism in cotyledons of germinating Lupinus albus L. seeds. Planta 203, 26-34. doi: 10.1007/s00050161

Reddy et al., 2007. Identification of antifungal component in clove that inhibits Aspergillus spp. colonizing rice grains. J. Mycol. Pl. Path . 37(1), 87-94.

Santos, C., Ferreira, R.B. Teixeira, A., 1997. Seed proteins of Lupinus mutabilis. J. Agric. Food Chem. 45, 3821-3825.

Silva Barros, M., Assis Santos, D., Hamedan, J., 2007. Evaluation of susceptibility of Trichophyton mentagrophytes and Trichophyton rubrum clinical isolates to antifungal drugs using a modified CLSI microdilution method (M38-A). J. Med. Microbiol. 56 (4), $514-518$. https://doi.org/10.1099/jmm.0.46542-0

Sluis et al., 2001. Activity \& Concentration of Polyphenolic Antioxidants in Apple: Effects of Cultivar, Harvest Year and Storage Conditions. J. Agric. Food Chem. 49, 3606-3613. https://doi.org/10.1021/jf001493u

Tylianakis et al., 2008. Global change and species interactions in terrestrial ecosystems. Ecol. Lett. 11, 1351-1363. doi:10.1111/j.14610248.2008.01250.x 
Table 1

Content of BCO ( $\mu \mathrm{g} \mathrm{mg}^{-1}$ fresh weight) in the plantlet cotyledons of seven L. albus cultivars.

\begin{tabular}{|c|c|c|c|c|c|c|c|c|c|c|c|c|c|c|}
\hline \multirow{3}{*}{ Time (DAG) } & \multicolumn{14}{|c|}{$\mathrm{BCO}\left(\mu \mathrm{g} \mathrm{mg}^{-1}\right.$ fresh weight) } \\
\hline & \multicolumn{2}{|c|}{ AMIGA } & \multicolumn{2}{|c|}{ ENERGY } & \multicolumn{2}{|c|}{ ESTORIL } & \multicolumn{2}{|c|}{ LUDIC } & \multicolumn{2}{|c|}{ MISAK } & \multicolumn{2}{|c|}{ MULTITALIA } & \multicolumn{2}{|c|}{ RUMBO } \\
\hline & Mean (SE) & HG & Mean (SE) & HG & Mean (SE) & HG & Mean (SE) & HG & Mean (SE) & HG & Mean (SE) & HG & Mean (SE) & HG \\
\hline 4 & $17.32(0.07)$ & a & $31.67(0.05)$ & a & $13.13(0.08)$ & a & $15.21(1.09)$ & a & $22.12(0.55)$ & $\mathrm{a}$ & $9.35(0.33)$ & $\mathrm{a}$ & $25.67(0.26)$ & a \\
\hline 5 & $17.14(0.05)$ & a & $26.49(0.05)$ & $\mathrm{b}$ & $13.20(0.16)$ & a & $13.48(0.24)$ & $a b$ & $16.16(0.57)$ & $\mathrm{b}$ & $7.20(0.67)$ & $\mathrm{ab}$ & $21.67(0.12)$ & $\mathrm{b}$ \\
\hline 6 & $16.41(0.49)$ & $\mathrm{a}$ & $14.86(0.82)$ & $\mathrm{c}$ & $9.93(0.69)$ & $\mathrm{b}$ & $11.96(0.64)$ & $\mathrm{b}$ & $15.04(0.03)$ & $\mathrm{b}$ & $7.95(0.21)$ & $\mathrm{ab}$ & $17.89(0.63)$ & $\mathrm{c}$ \\
\hline 7 & $13.46(0.82)$ & $\mathrm{b}$ & $13.73(0.30)$ & $\mathrm{c}$ & $7.70(0.13)$ & $\mathrm{c}$ & $5.78(0.13)$ & $\mathrm{c}$ & $10.32(0.29)$ & $\mathrm{c}$ & $6.64(0.07)$ & $\mathrm{bc}$ & $11.70(0.29)$ & d \\
\hline 8 & $11.57(0.03)$ & $\mathrm{bc}$ & $10.96(0.46)$ & $\mathrm{d}$ & $3.29(0.09)$ & $\mathrm{d}$ & $4.53(0.33)$ & $\mathrm{cd}$ & $8.45(0.11)$ & $\mathrm{d}$ & $6.22(0.20)$ & $\mathrm{bc}$ & $12.30(0.04)$ & $\mathrm{d}$ \\
\hline 9 & $9.96(0.88)$ & $\mathrm{c}$ & $9.13(0.40)$ & $\mathrm{d}$ & $3.11(0.06)$ & $\mathrm{d}$ & $4.75(0.35)$ & $\mathrm{cd}$ & $9.27(0.08)$ & $\mathrm{d}$ & $5.80(0.18)$ & $\mathrm{bc}$ & $9.09(0.09)$ & e \\
\hline 10 & $7.88(0.18)$ & $\mathrm{d}$ & $9.13(1.19)$ & $\mathrm{d}$ & $4.28(0.05)$ & $\mathrm{d}$ & $2.93(0.26)$ & de & $6.62(0.53)$ & $\mathrm{e}$ & $5.75(0.18)$ & $\mathrm{bc}$ & $7.73(0.03)$ & $\mathrm{f}$ \\
\hline 11 & $4.55(0.19)$ & $\mathrm{e}$ & $5.66(0.55)$ & e & $2.21(0.02)$ & e & $3.02(0.19)$ & de & $4.26(0.18)$ & $\mathrm{f}$ & $4.50(0.30)$ & $\mathrm{cd}$ & $8.32(0.13)$ & $\mathrm{f}$ \\
\hline 12 & $4.98(0.05)$ & $\mathrm{e}$ & $4.56(0.14)$ & $\mathrm{e}$ & $2.18(0.04)$ & $\mathrm{e}$ & $1.41(0.03)$ & $\mathrm{e}$ & $4.85(0.08)$ & $\mathrm{f}$ & $2.49(1.05)$ & d & $4.27(0.10)$ & $\mathrm{g}$ \\
\hline ANOVA & \multicolumn{4}{|c|}{ Time factor } & \multicolumn{5}{|c|}{ Time:Cultivar interaction } & \multicolumn{5}{|c|}{ Cultivar factor } \\
\hline $\mathrm{F}$ & \multicolumn{4}{|c|}{1138.99} & \multicolumn{5}{|c|}{79.77} & \multicolumn{5}{|c|}{504.92} \\
\hline P-value & \multicolumn{4}{|c|}{$<2 \mathrm{E}-16$} & \multicolumn{4}{|c|}{$<2 \mathrm{E}-16$} & & \multicolumn{5}{|c|}{$<2 \mathrm{E}-16$} \\
\hline
\end{tabular}


Table 2

BCO quantitative assay from various seed lots of L. albus cvs. Energy and Misak in 4-day-old cotyledons produced under different edaphoclimatic conditions (different harvest years and/or origin sites in Portugal).

\begin{tabular}{|c|c|c|c|c|}
\hline \multirow{3}{*}{ Lot } & \multicolumn{4}{|c|}{$\mathrm{BCO}\left(\mu \mathrm{g} \mathrm{mg}^{-1}\right.$ fresh weight) } \\
\hline & \multicolumn{2}{|c|}{ ENERGY } & \multicolumn{2}{|r|}{ MISAK } \\
\hline & Mean (SE) & Homogeneous Groups & Mean (SE) & Homogeneous Groups \\
\hline Alto Alentejo & $8.97(5.18)$ & $\mathrm{b}$ & $51.26(29.60)$ & $\mathrm{a}$ \\
\hline Baixo Alentejo & $7.49(4.32)$ & $\mathrm{c}$ & $36.64(21.16)$ & $\mathrm{b}$ \\
\hline Beira Litoral & $10.16(5.86)$ & $\mathrm{a}$ & $36.72(21.20)$ & $\mathrm{b}$ \\
\hline ISA 2014 & $6.83(3.94)$ & d & $5.89(3.40)$ & $\mathrm{e}$ \\
\hline ISA 2010 & - & - & $12.92(7.46)$ & $\mathrm{d}$ \\
\hline ISA 1997 & - & - & $33.80(19.52)$ & $\mathrm{c}$ \\
\hline ANOVA & Lot Factor & Time:Cultivar interaction & \multicolumn{2}{|r|}{ Cultivar factor } \\
\hline $\mathrm{F}$ & 865.8 & 760.2 & \multicolumn{2}{|r|}{4961.2} \\
\hline$P$-value & $<2 \mathrm{E}-16$ & $<2 \mathrm{E}-16$ & \multicolumn{2}{|r|}{$<2 \mathrm{E}-16$} \\
\hline
\end{tabular}


Table 3

BCO antifungal activity. L. albus cvs Energy and Rumbo seeds days after the onset of germination. No antifungal activity was detected for the negative control (absence of BCO).

Minimum Inhibitory Concentration (MIC, $\mu \mathrm{g} \mathrm{mL}^{-1}$ )

\begin{tabular}{|c|c|c|c|c|c|c|c|c|}
\hline \multirow{3}{*}{$\begin{array}{l}\text { Fungal Species } \\
\text { Time (DAG) }\end{array}$} & \multicolumn{4}{|c|}{ Botrytis cinerea } & \multicolumn{4}{|c|}{ Candida glabrata } \\
\hline & \multicolumn{2}{|c|}{ ENERGY } & \multicolumn{2}{|c|}{ RUMBO } & \multicolumn{2}{|c|}{ ENERGY } & \multicolumn{2}{|c|}{ RUMBO } \\
\hline & Mean (SE) & $\mathrm{HG}$ & Mean (SE) & $\mathrm{HG}$ & Mean (SE) & $\mathrm{HG}$ & Mean (SE) & $\mathrm{HG}$ \\
\hline 3 & $93.75(31.25)$ & $\mathrm{b}$ & $270.83(126.72)$ & $\mathrm{b}$ & $208.33(41.67)$ & $\mathrm{b}$ & $125.00(62.50)$ & $\mathrm{b}$ \\
\hline 4 & $135.42(63.36)$ & $\mathrm{b}$ & $135.42(63.36)$ & $\mathrm{b}$ & $93.75(31.25)$ & $\mathrm{b}$ & 208.33 (41.67) & $\mathrm{b}$ \\
\hline 5 & $125(0)$ & $\mathrm{b}$ & $541.67(253.45)$ & $\mathrm{b}$ & $145.83(55.12)$ & $\mathrm{b}$ & $333.33(83.33)$ & $\mathrm{b}$ \\
\hline 8 & $>500$ & $\mathrm{a}$ & $>500$ & $\mathrm{a}$ & $>500$ & $\mathrm{a}$ & $>500$ & a \\
\hline 12 & $>500$ & $\mathrm{a}$ & $>500$ & a & $>500$ & $\mathrm{a}$ & $>500$ & $\mathrm{a}$ \\
\hline 16 & $>500$ & $\mathrm{a}$ & $>500$ & $\mathrm{a}$ & $>500$ & $\mathrm{a}$ & $>500$ & $\mathrm{a}$ \\
\hline ANOVA & \multicolumn{2}{|c|}{ Time factor } & \multicolumn{2}{|c|}{ Cultivar factor } & \multicolumn{2}{|c|}{ Time factor } & \multicolumn{2}{|c|}{ Cultivar factor } \\
\hline $\mathrm{F}$ & \multicolumn{2}{|c|}{33.75} & \multicolumn{2}{|c|}{5.81} & \multicolumn{2}{|c|}{33.65} & \multicolumn{2}{|c|}{5.8} \\
\hline P-value & \multicolumn{2}{|c|}{$3.07 \mathrm{E}-11$} & \multicolumn{2}{|c|}{0.02} & \multicolumn{2}{|c|}{$3.19 \mathrm{E}-11$} & \multicolumn{2}{|c|}{0.02} \\
\hline
\end{tabular}


340 Fig. 1

341

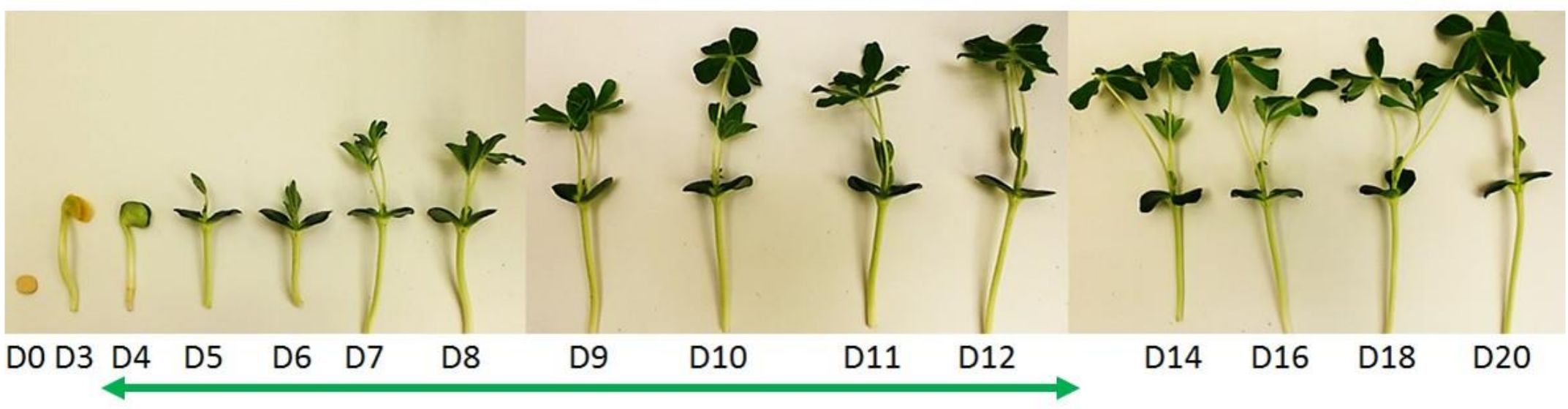


347

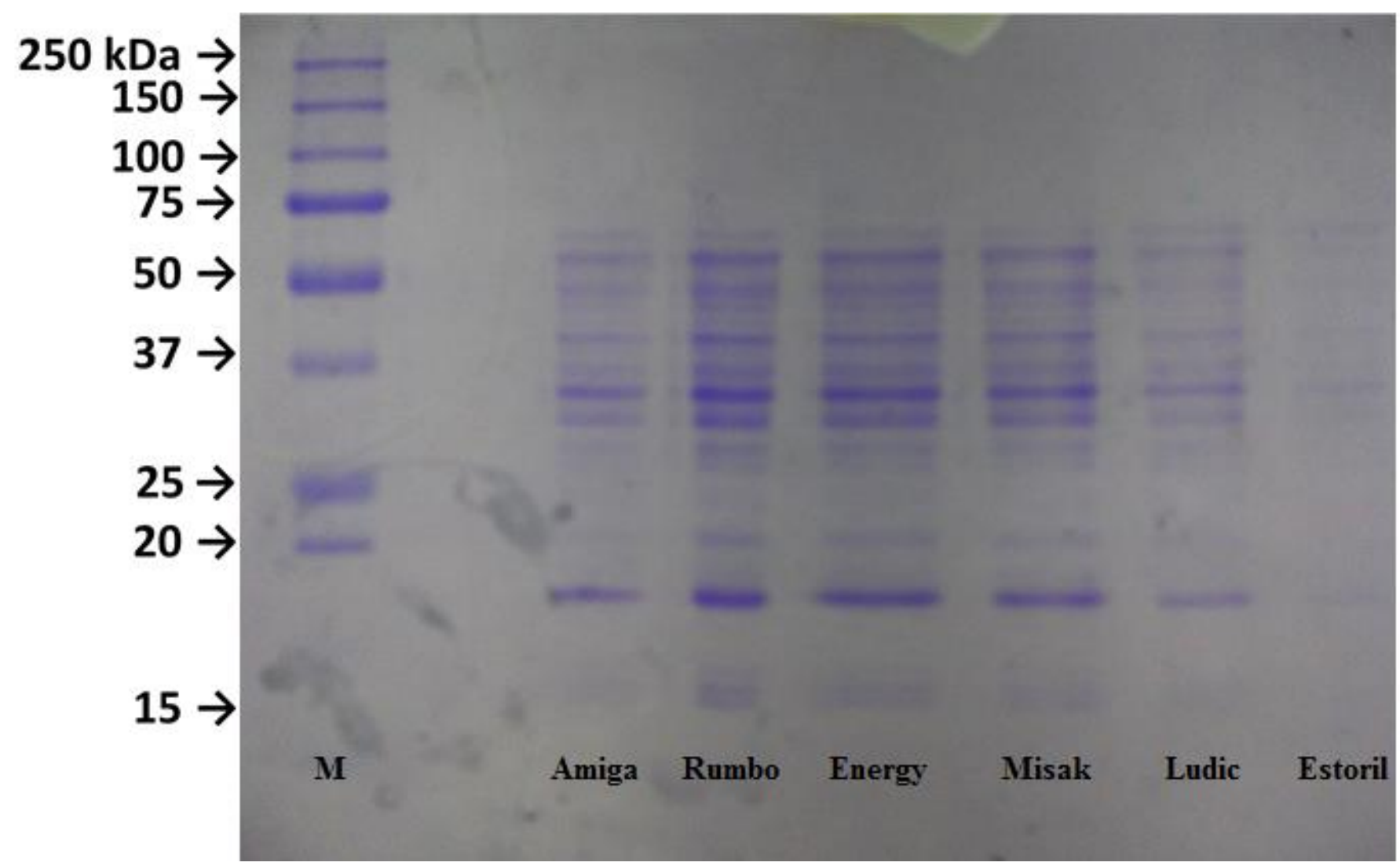

349 
351 Fig. 3A

352

353

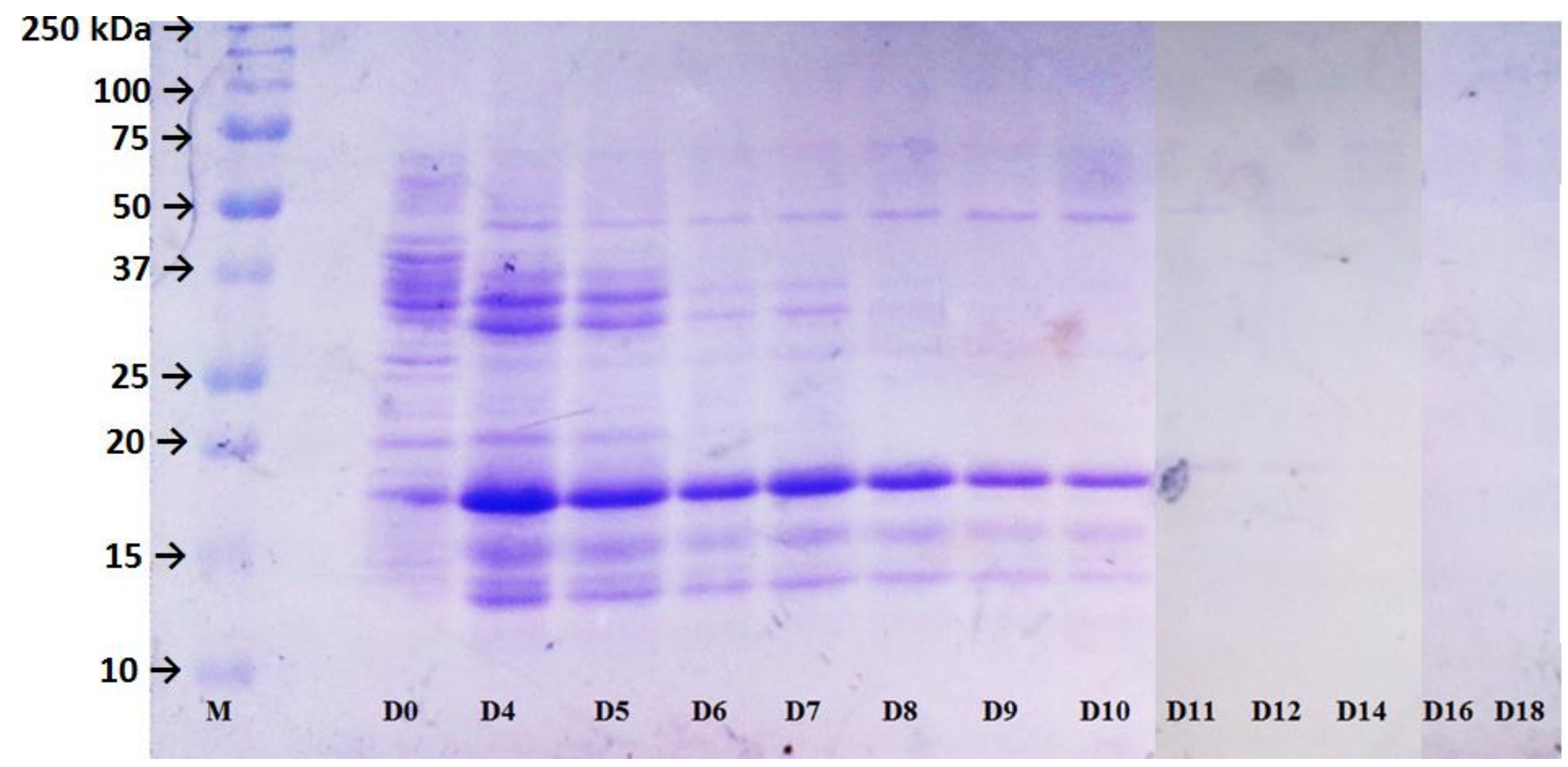

355 


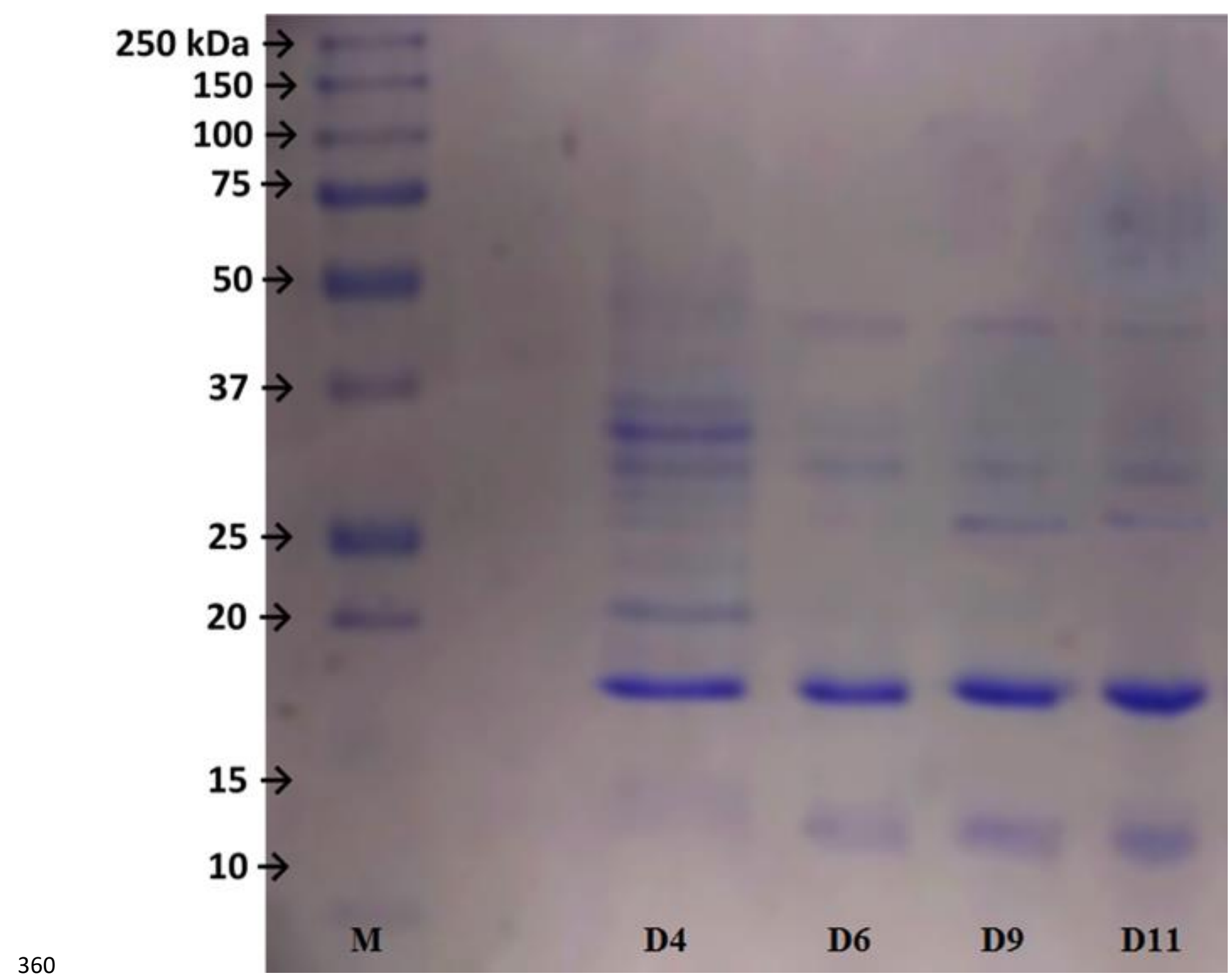

361 
Fig. 1. Development stages of $L$. albus during the first 20 days after the onset of germination The green line indicates the presence of $\mathrm{BCO}$ in the cotyledons.

Fig. 2. Comparative quantitative and structural SDS-PAGE analyses of BCO purified from the cotyledons of six L. albus cultivars 4 days after the onset of germination. L. albus seeds were germinated and grown for four days and BCO extracted, purified, analyzed by onedimensional SDS-PAGE and stained for total polypeptides. The volume loaded in each lane $(22.78 \mu \mathrm{L})$ corresponded to $20 \mu \mathrm{g}$ of BCO for the cultivar Energy. The cultivars analysed are indicated in the bottoom of the gel. Molecular masses of standards are indicated in kDa.

Fig. 3. One-dimensional structural analysis of BCO from L. albus, cv. Energy. L. albus seeds were germinated and grown for up to 18 days and BCO extracted, purified, analyzed by one-dimensional SDS-PAGE and stained for total polypeptides. (A) - Purified BCO extract (22.78 $\mu \mathrm{L}$; see legend to Figure 2) was loaded in each lane. (B) - Purified BCO $(20 \mu \mathrm{g})$ was loaded in each lane. Days after the onset of germination are indicated in the bottoom of the gel. Molecular masses of standards are indicated in $\mathrm{kDa}$. 